\title{
Substituição do Milho por Farelo de Palma Forrageira em Dietas de Ovinos em Crescimento. Desempenho ${ }^{1}$
}

\author{
Robson Magno Liberal Véras ${ }^{2}$, Marcelo de Andrade Ferreira ${ }^{3,4}$, Carmen Valéria de Araújo \\ Cavalcanti ${ }^{5}$, Antonia Sherlânea Chaves Véras ${ }^{3}$, Francisco Fernando Ramos de Carvalho ${ }^{3}$, \\ Gladston Rafael Arruda dos Santos ${ }^{6}$, Kaliandra Souza Alves ${ }^{6}$, Rinaldo José de Souto Maior Júnior ${ }^{7}$
}

RESUMO - Objetivou-se, com este trabalho, avaliar quatro níveis de substituição do milho (0; 33; 67 e 100\%) pelo farelo de palma forrageira sobre o desempenho de ovinos em crescimento terminados em confinamento. Vinte carneiros mestiços Santa Inês foram distribuídos em delineamento em blocos ao acaso, com quatro tratamentos (níveis de substituição do milho pelo farelo de palma) e cinco repetições. Além do milho e/ou farelo de palma, os animais receberam feno de Tifton (Cynodon dactylon), como volumoso, farelo de soja, calcário e sal mineral. O ganho de peso e a conversão alimentar diminuíram, enquanto os consumos de FDN e de FDA aumentaram linearmente com a substituição. Os consumos de matéria seca, de proteína bruta, de matéria orgânica e de carboidratos totais e o rendimento de carcaça não foram influenciados pela substituição do milho pelo farelo de palma.

Palavras-chave: carcaça, consumo, ganho de peso

\section{Replacement of Corn by Forage Cactus Meal in Growing Lambs Diets. Performance}

\begin{abstract}
The objective of this work was to evaluate four corn replacement levels (0,33, 67 and 100\%) by forage cactus meal on performance of feedlot growing lambs. Twenty crossbred lambs were allotted to a completely randomized block design with four treatments (replacement of corn by forage cactus meal) and five replications. Besides corn and/or forage cactus meal, the animals were fed Tifton hay (Cynodon dactylon), as forage, soybean meal, limestone and mineral salt. Weight gain and feed:gain ratio decreased and intakes of NDF and ADF increased linearly with corn replacement. The intakes of dry matter, crude protein, organic matter and total carbohydrates and carcass yield were not affected by replacement of corn by forage cactus meal.
\end{abstract}

Key Words: carcass, intake, live weight gain

\section{Introdução}

Atualmente, a ovinocultura no Brasil é uma alternativa de exploração pecuária que vem alcançando grande desenvolvimento, principalmente quanto à produção de carne.

Tem-se notado interesse em intensificar a terminação de cordeiros em confinamento, objetivando rapidez para a comercialização, sobretudo na época da entressafra. No entanto, as rações apresentam elevada quantidade de volumoso, o que resulta em baixos ganhos. Dessa forma, para que os ovinos exteriorizem seu potencial produtivo, faz-se necessário o balanceamento das dietas de modo a atender plenamente suas exigências nutricionais (Alves et al., 2003).
Existe hoje uma variedade de alimentos que podem ser utilizados na alimentação de ruminantes. Entretanto, seu valor nutricional e sua qualidade são determinados por complexa interação entre os nutrientes e os microrganismos do trato digestivo, nos processos de digestão, absorção, transporte e utilização de metabólitos, além da própria condição fisiológica do animal (Martins et al., 2000).

Ovinos em crescimento apresentam alta exigência em nutrientes que, geralmente, não são encontrados em níveis adequados em dietas constituídas somente por volumosos. Portanto, é necessária a suplementação com concentrados, que, normalmente, têm preço elevado, aumentando o custo de produção.

\footnotetext{
1 Trabalho parcialmente financiado pela FACEPE, parte da dissertação do primeiro autor apresentada ao Programa de Pós-Graduação em Zootecnia da UFRPE.

2 Aluno do Programa de Pós-Graduação em Zootecnia da UFV (rmlv2002@yahoo.com.br).

3 Professores do Depto de Zootecnia - UFRPE. E.mail: ferreira@ufrpe.br

${ }^{4}$ Bolsista do CNPq.

${ }^{5}$ Aluna do Programa de Pós-Graduação em Zootecnia da UFRPE.

${ }^{6}$ Aluno do Programa de Doutorado Integrado em Zootecnia - UFRPE.

${ }^{7}$ Aluno de Graduação em Zootecnia da UFRPE.
} 
Um dos principais alimentos utilizados na formulação de concentrados é o milho. Porém, apesar de sua boa qualidade, muitas pesquisas são realizadas com o objetivo de estudar alternativas para sua substituição em dietas dos ruminantes (Ramos et al., 2000) por nem sempre ser economicamente viável e, às vezes, poder ocasionar distúrbios fisiológicos nos animais, como o aumento na produção de ácido láctico, levando à diminuição do $\mathrm{pH}$ e redução na atividade das bactérias celulolíticas, resultando em queda na digestibilidade (Van Soest et al., 1991).

$\mathrm{Na}$ busca por produtos substitutos do milho, Dhakad et al. (2002) trabalharam com a substituição do milho moído pelo trigo na alimentação de ovinos em crescimento e concluíram que o milho pode ser substituído em até 50\% no concentrado. Garcia et al. (1997) concluíram que o ganho médio diário de cordeiros não foi influenciado pela substituição do milho em até $33 \%$ por sorgo-vassoura.

A palma forrageira é a base da alimentação de ruminantes no semi-árido pernambucano, principalmente na época seca, por ser uma cultura adaptada às condições edafoclimáticas e apresentar altas produções de matéria seca por unidade de área (Santos et al., 1997), além de ser uma excelente fonte de carboidratos não-fibrosos (Wanderley et al., 2002) e nutrientes digestíveis totais (Melo et al., 2003).

Comparativamente a outros alimentos, o teor de fibra na palma é baixo, principalmente a fração lignina-celulose (Santos et al., 2000), e o percentual de carboidratos solúveis é alto (Nefzaoui \& Ben Salen, 2003). No entanto, apesar de os carboidratos solúveis serem rápidos e extensivamente fermentados no rúmen, as características de fermentação diferem entre si, por serem, em grande parte, ácidos orgânicos. A digestão da pectina, por exemplo, resulta em menor produção de ácido láctico (Strobel \& Russel, 1986) que o amido (carboidrato solúvel) presente em grande quantidade no milho.

Andrade et al. (2002) verificaram comportamento quadrático para digestibilidade dos nutrientes e teor de NDT, quando substituíram a silagem de sorgo por palma forrageira em dietas para vacas em lactação. Araújo (2002) não observou alteração no desempenho de vacas mestiças em lactação, substituindo $100 \%$ do milho do concentrado por palma forrageira. Véras et al. (2002) substituíram até 75\% do milho por farelo de palma em dietas restritas $(2,5 \%$ do peso vivo) para ovinos e não observaram alteração na digestibilidade dos nutrientes e no teor de NDT.
O consumo voluntário é a quantidade de alimentos ingerido por um animal durante determinado período em que tem livre acesso ao alimento (Forbes, 1995). É uma das variáveis mais importantes que afetam o desempenho animal, podendo ser influenciada por características do animal, do alimento e das condições de alimentação (Mertens, 1992).

O consumo e a digestibilidade de nutrientes podem estar correlacionados, dependendo da qualidade da ração, pois a digestibilidade é uma descrição qualitativa do consumo. Para rações com teor de FDN menor que $25 \%$, o consumo será menor quanto mais digestível for o alimento, regulado pelos fatores fisiológicos e, em ração com mais de $75 \%$ de FDN, o consumo será maior quanto melhor for a digestibilidade do alimento. Neste caso, a ingestão de MS é controlada por fatores físicos (Mertens, 1994; Van Soest, 1994).

A avaliação de carcaça - importante na avaliação do desempenho alcançado pelo animal durante seu desenvolvimento - é determinada a partir do consumo, do ganho de peso, da conversão alimentar e do rendimento de carcaça (Santos et al., 2001).

No sistema de produção de carne, as características quantitativas da carcaça são de fundamental importância, pois estão diretamente relacionadas ao produto final - carne, cuja qualidade e quantidade dependem de fatores relativos ao meio e à nutrição.

Este trabalho foi conduzido com o objetivo de avaliar o desempenho e as características de carcaça de ovinos alimentados com dietas contendo quatro níveis de substituição $(0,33,67$ e $100 \%)$ do milho moído pelo farelo de palma.

\section{Material e Métodos}

Este experimento foi desenvolvido no Departamento de Zootecnia da Universidade Federal Rural de Pernambuco.

Vinte carneiros mestiços (peso médio inicial de $20 \mathrm{~kg}$ e idade aproximadade 6 meses) foram distribuídos em blocos casualizados, em que o peso vivo inicial foi adotado como fator de blocagem. Os animais foram mantidos em baias individuais $(1,1 \times 0,55 \mathrm{~m})$, provida de comedouro, bebedouro e cocho para sal, onde permaneceram até atingirem peso médio de abate estabelecido em $32 \mathrm{~kg}$.

Os tratamentos experimentais consistiram da substituição do milho pelo farelo de palma nos níveis 0, 33, 66 e 100\%. A composição percentual dos 
ingredientes nas dietas experimentais e a composição bromatológica dos alimentos encontram-se, respectivamente, nas Tabelas 1 e 2 .

O farelo de palma foi confeccionado na Estação Experimental de Serra Talhada - PE, pertencente à Empresa Pernambucana de Pesquisa Agropecuária - IPA. A palma utilizada foi o cultivar Gigante da espécie (Opuntia fícus indica, Mill), picada, seca ao sol por três dias e moída para obtenção do farelo. Os demais concentrados utilizados foram adquiridos comercialmente.

O volumoso utilizado foi o feno de Tifton- 85 (Cynodon dactylon), adquirido em casa comercial na forma de fardos de $14 \mathrm{~kg}$ cada e triturado em máquina forrageira, sendo reduzido a partículas de $5 \mathrm{~cm}$ e armazenado em sacos.

Tabela 1 - Composição percentual dos ingredientes nas dietas (\% na MS)

Table 1 - Percentage of the ingredient in the diets (\% of DM)

\begin{tabular}{lcccc}
\hline $\begin{array}{l}\text { Ingredientes } \\
\text { Ingredients }\end{array}$ & \multicolumn{4}{c}{$\begin{array}{c}\text { Níveis de substituição (\%) } \\
\text { Levels of replacement } \%\end{array}$} \\
\cline { 2 - 5 } & 0 & 33 & 66 & 100 \\
\hline $\begin{array}{l}\text { Feno de Tifton } \\
\text { Tifton hay }\end{array}$ & 49,2 & 50,0 & 50,0 & 50,2 \\
$\begin{array}{l}\text { Milho } \\
\text { Corn }\end{array}$ & 28,3 & 18,8 & 9,4 & 0,0 \\
$\begin{array}{l}\text { Farelo de palma } \\
\text { Forage cactus meal }\end{array}$ & 0,0 & 9,4 & 18,9 & 28,3 \\
$\begin{array}{l}\text { Farelo de soja } \\
\text { Soybean meal }\end{array}$ & 21,5 & 21,5 & 21,5 & 21,5 \\
$\begin{array}{l}\text { Calcário } \\
\text { Limestone }\end{array}$ & 1,0 & 0,3 & 0,0 & 0,0 \\
Total & 100 & 100 & 100 & 100 \\
\hline
\end{tabular}

Suplemento mineral (mineral supplement): Ca-140,0 g; P-65,0 g; S-15,0 g; Mg- 15,0 g; Zn- 3.500,0 mg; Mn-3.000,0; I-60,0 mg; Se-10,0 mg; Co-100,0 mg; Vit A-50.000,0 Ul/kg; Fluor(máx)$650,0 \mathrm{mg}$.
As dietas foram fornecidas na forma de ração completa, duas vezes ao dia (50\% pela manhã e 50\% à tarde), com água e sal mineral permanentemente à disposição. A dieta com $0 \%$ de substituição do milho pelo farelo de palma foi formulada para atender aos requerimentos de ganho de peso médio diário de $200 \mathrm{~g} /$ animal/dia (NRC, 1985).

Os animais passaram por um período de adaptação às instalações e ao manejo (30 dias), quando foram feitos ajustes da quantidade dos alimentos ingeridos diariamente para medir o consumo máximo dos animais, para se obter sobras de 5 a $10 \%$, evitando a seleção dos alimentos pelos animais.

Amostras dos alimentos fornecidos (farelo de palma, milho, soja e feno de Tifton) foram coletadas sempre antes do preparo das rações experimentais. As sobras foram coletadas semanalmente por animal, pré-secas e homogeneizadas para obtenção da amostra composta do período de 28 dias. As amostras compostas foram submetidas a análises de matéria seca (MS), de proteína bruta (PB), de fibra em detergente ácido (FDA), de extrato etéreo (EE) e de matéria orgânica (MO), segundo Silva \& Queiroz (2002). As determinações de fibra em detergente neutro (FDN) foram realizadas de acordo com metodologia proposta Van Soest et al. (1991).

As pesagens dos animais foram realizadas a cada 28 dias, entretanto, ocorreram pesagens intermediárias, quando o peso vivo se aproximava dos $32 \mathrm{~kg}$ (peso de abate). Os animais, quando atingiram o peso pré-estabelecido de abate, passaram a receber somente dieta hídrica por 14 horas. No momento do abate, os animais foram insensibilizados por descarga elétrica, seguida por sangria, através da seção das carótidas e jugular. Após a esfola, evisceração, retirada da cabeça, patas e órgãos genitais, foi obtido o peso da carcaça quente (PCQ).

Tabela 2 - Composição químico-bromatológica dos ingredientes das dietas (\%MS)

Table 2 - Chemical composition of the ingredients of diets (\% DM)

\begin{tabular}{|c|c|c|c|c|c|}
\hline \multicolumn{6}{|c|}{ Ingredientes (Ingredients) } \\
\hline Itens & Milho & Farelo de palma & Farelo de soja & Feno de Tifton & Calcário \\
\hline Items & Corn & Forage cactus meal & Soybean meal & Tifton hay & Limestone \\
\hline$\overline{M S}(\%)(D M \%)$ & 86,05 & 90,0 & 88,72 & 87,57 & 99 \\
\hline $\mathrm{MO}^{1}(O M)$ & 97,12 & 98,89 & 93,12 & 93,14 & - \\
\hline $\operatorname{EE}^{1}(\%)$ & 3,54 & 1,69 & 1,84 & 1,76 & - \\
\hline $\mathrm{PB}^{1}(C P)$ & 8,5 & 6,95 & 48,67 & 8,0 & - \\
\hline $\mathrm{FDN}^{1}(N D F)$ & 15,28 & 29,95 & 19,0 & 72,42 & - \\
\hline $\mathrm{FDA}^{1}(A D F)$ & 3,6 & 15,0 & 12,0 & 42,8 & - \\
\hline $\mathrm{Ca}^{1}$ & 0,17 & 20,7 & 2,6 & 3,7 & 360 \\
\hline $\mathrm{P}^{1}$ & 2,6 & 1,8 & 6,3 & 1,57 & - \\
\hline
\end{tabular}

$1 \%$ na MS (\% in DM).

R. Bras. Zootec., v.34, n.1, p.249-256, 2005 
Posteriormente, as carcaças foram resfriadas por 24 horas a $\pm 4^{\circ} \mathrm{C}$, penduradas pela articulação tarso metatarsiano, em ganchos próprios, obtendo-se o peso da carcaça fria (PCF). Os dados obtidos também possibilitaram o cálculo da perda por resfriamento $(\mathrm{PR})$ : PR $(\%)=((\mathrm{PCQ}-\mathrm{PCF})$ x 100/PCQ).

Os dados foram submetidos a análises de variância e de regressão, em função dos níveis de substituição do milho pelo farelo de palma, por intermédio do SAEG - Sistemas de Análises Estatísticas e Genéticas (UFV, 1997).

\section{Resultados e Discussão}

As médias, as equações de regressão (ER) e os coeficientes de determinação $\left(r^{2}\right)$ e variação $(C V)$ referentes ao consumo de nutrientes, em função dos níveis de substituição do milho moído pelo farelo de palma, são apresentados na Tabela 4.

Não houve efeito da inclusão do farelo de palma $(\mathrm{P}>0,05)$ sobre o consumo de matéria seca (CMS). A palma forrageira apresenta alta palatabilidade, com grande aceitação pelos animais e, por isso, o farelo não perde esta característica. Outro fator importante é que a palma, diferentemente de outras forragens, apresenta alta taxa de digestão ruminal, sendo a matéria seca degradada extensa e rapidamente, favorecendo maior taxa de passagem e, conseqüentemente, consumo semelhante ao dos concentrados (Silva et al., 1997).

No entanto, o CMS, expresso em quilograma por dia $(\mathrm{kg} / \mathrm{dia})$, pode ser considerado relativamente alto, em comparação aos preditos pelo NRC (1985), que sugere valores de, aproximadamente, $1,0 \mathrm{~kg}$ de MS/dia, para animais de $25 \mathrm{~kg}$ de PV e ganho diário de $200 \mathrm{~g}$. Vale ressaltar que estas tabelas foram confeccionadas a partir de dietas com maiores teores de energia.

Os valores encontrados neste trabalho para consumo de MS, em porcentagem do peso vivo, estão acima dos verificados por Geron et al. (2001), quando substituíram o milho pela farinha de varredura em dietas de ovinos (2,9\% PV). Da mesma forma, Garcia et al. (2000), usando casca de café na dieta de ovinos, encontraram consumo de matéria seca de $76 \mathrm{~g} / \mathrm{kg}^{0}, 75 / \mathrm{dia}$, valor menor que os encontrados neste trabalho.

Não foi verificado efeito da substituição do milho por farelo de palma $(\mathrm{P}>0,05)$ para os consumos de proteína bruta $(\mathrm{CPB})$, matéria orgânica $(\mathrm{CMO}) \mathrm{e}$ carboidratos totais (CCHOT). Estes resultados po- dem ser explicados pelo fato de as dietas terem níveis semelhantes destes nutrientes e da ausência de efeito no CMS (Tabelas 3 e 4, respectivamente). Comportamento semelhante foi observado por Zeoula et al. (2000), em ovinos, trabalhando com substituição do milho pela farinha de varredura (Manihot sculenta) sobre consumo de MS, PB e MO. Ramos et al. (2000), ao fornecerem bagaço de mandioca em substituição ao milho no concentrado para bovinos em crescimento, também não observaram diferença no CMS, CMO e CPB até o nível de $45 \%$ de substituição.

Os consumos de FDN e de FDA aumentaram $(\mathrm{P}<0,05)$ linearmente com a substituição do milho moído pelo farelo de palma, o que também pode ser explicado pelo aumento da concentração destes componentes nas dietas (Tabela 3).

Comportamento inverso foi detectado para consumo de nutrientes digestíveis totais (CNDT), que diminuiu linearmente $(\mathrm{P}<0,05)$ com o aumento nos níveis de farelo de palma da ração (Tabela 4). Esse fato pode ser explicado pela diminuição nos teores de nutrientes digestíveis totais, que foi menor para os tratamentos com maiores percentuais de farelo de palma (Tabela 3 ) e consumo de matéria seca semelhante.

As médias, as equações de regressão (ER) e oscoeficientes de determinação $\left(\mathrm{r}^{2}\right)$ e variação $(\mathrm{CV})$ referentes ao ganho de peso diário (GPD), rendi-

Tabela 3 - Teores de matéria seca (MS), matéria orgânica (MO), proteína bruta (PB), extrato etéreo (EE), fibra em detergente neutro (FDN), fibra em detergente ácido (FDA), carboidratos totais (CHOT) e nutrientes digestíveis totais (NDT) das rações experimentais

Table 3 - Contents of dry matter (DM), organic matter (OM), crude protein $(C P)$, ether extract $(E E)$, neutral detergent fiber (NDF), acid detergent fiber (ADF), total carbohydrates (TC) and total digestible nutrientes (TDN) of the diets

\begin{tabular}{lcccr}
\hline \multirow{2}{*}{$\begin{array}{l}\text { Nutrientes } \\
\text { Nutrients }\end{array}$} & \multicolumn{4}{c}{$\begin{array}{c}\text { Níveis de substituição (\%) } \\
\text { Levels of replacement }(\%)\end{array}$} \\
\cline { 2 - 5 } & 0 & 33 & 66 & 100 \\
\hline MS\% $(D M \%)$ & 86,92 & 87,32 & 87,12 & 87,28 \\
$\mathrm{MO}^{1}\left(O M^{1}\right)$ & 93,83 & 92,26 & 91,03 & 89,32 \\
$\mathrm{~PB}^{1}\left(C P^{1}\right)$ & 18,40 & 18,18 & 17,77 & 17,51 \\
$\mathrm{EE}^{1}\left(E E^{1}\right)$ & 1,09 & 1,37 & 1,34 & 1,34 \\
$\mathrm{FDN}^{1}\left(N D F^{1}\right)$ & 52,78 & 55,11 & 56,57 & 58,70 \\
$\mathrm{FDA}^{1}\left(A D F^{1}\right)$ & 25,12 & 27,39 & 29,13 & 30,88 \\
$\mathrm{CHOT}^{1}\left(T C^{1}\right)$ & 74,34 & 72,74 & 71,91 & 70,46 \\
NDT $(\%)(T D N \%)$ & 62,88 & 60,53 & 54,78 & 51,35 \\
\hline
\end{tabular}

$1 \%$ na matéria seca (\% in DM). 
Tabela 4 - Médias, equação de regressão ajustada (ER), coeficientes de determinação ( $\left.\mathrm{r}^{2}\right)$ e variação (CV) do consumo de matéria seca (CMS), matéria orgânica (CMO), proteína bruta (CPB), fibra em detergente neutro (CFDN), fibra em detergente ácido (CFDA), carboidrato total (CCHOT) e nutrientes digestíveis totais (CNDT), em função dos níveis de substituição do milho pelo farelo de palma

Table 4 - Mean, fitted regression equation (RE), coefficients of determination ( $\left.r^{2}\right)$ and variation (CV) for dry matter (DMI), organic matter (OMI), crude protein (CPI), neutral detergent fiber (NDFI), acid detergent fiber (ADF), total carbohydrates (TC) and total digestible nutrientes (TDN), according to the levels of replacement of corn by forage cactus meal

\begin{tabular}{|c|c|c|c|c|c|c|c|}
\hline \multirow[t]{2}{*}{$\begin{array}{l}\text { Variáveis } \\
\text { Variables }\end{array}$} & \multicolumn{4}{|c|}{$\begin{array}{l}\text { Níveis de substituição (\%) } \\
\text { Levels of replacement }(\%)\end{array}$} & \multirow[t]{2}{*}{$\mathrm{ER}$} & \multirow[t]{2}{*}{$r^{2}$} & \multirow[t]{2}{*}{$\mathrm{CV}(\%)$} \\
\hline & 0 & 33 & 66 & 100 & & & \\
\hline $\begin{array}{l}\text { CMS (kg/dia) } \\
\text { DMI (kg/day) }\end{array}$ & 1,17 & 1,10 & 1,19 & 1,14 & $Y=1,15$ & - & 6,81 \\
\hline $\begin{array}{l}\text { CMS (\%PV) } \\
D M I(\% L W)\end{array}$ & 4,27 & 4,11 & 4,36 & 4,22 & $Y=4,24$ & - & 5,52 \\
\hline $\begin{array}{l}\text { CMS }\left(\mathrm{g} / \mathrm{kg}^{0,75}\right) \\
D M I\left(g / \mathrm{kg}^{.75}\right)\end{array}$ & 97,88 & 93,62 & 99,79 & 96,24 & $Y=96,88$ & - & 5,77 \\
\hline $\begin{array}{l}\mathrm{CMO}(\mathrm{kg} / \mathrm{dia}) \\
\text { OMI (kg/day) }\end{array}$ & 1,03 & 1,02 & 1,08 & 1,01 & $Y=1,03$ & - & 11,78 \\
\hline $\begin{array}{l}\text { CPB (kg/dia) } \\
\text { CPI (kg/day) }\end{array}$ & 0,215 & 0,214 & 0,224 & 0,213 & $Y=0,217$ & - & 11,34 \\
\hline $\begin{array}{l}\text { CFDN (kg/dia) } \\
\text { NDFI (kg/day) }\end{array}$ & 0,452 & 0,480 & 0,539 & 0,539 & $\begin{array}{l}Y=0,45529+0,00096208 * \mathrm{FP} \\
\text { (n) }\end{array}$ & 0,90 & 11,93 \\
\hline $\begin{array}{l}\text { CFDA (kg/dia) } \\
A D F I(\mathrm{~kg} / \text { day })\end{array}$ & 0,223 & 0,251 & 0,287 & 0,301 & $Y=0,22531+0,0008151 * \mathrm{FP}$ & 0,98 & 10,62 \\
\hline $\begin{array}{l}\text { CCHOT (kg/dia) } \\
\text { TCI (kg/day) }\end{array}$ & 0,806 & 0,790 & 0,840 & 0,780 & $Y=0,810$ & - & 12,15 \\
\hline $\begin{array}{l}\text { CNDT (kg/dia) } \\
\text { TDNI (kg/day) }\end{array}$ & 0,74 & 0,67 & 0,63 & 0,58 & $Y=0,70042-0,0010771 * \mathrm{FP}$ & 0,97 & 11,24 \\
\hline
\end{tabular}

* Significativo $(P<0,05)$ pelo teste $\mathrm{t}$ (Significant $[P<.05]$ by $t$ test $)$. FP - Nível de substituição (Level of replacement).

mentos de carcaça quente (RCQ) e fria (RCF), perda por resfriamento (PR), dias em confinamento (DC) e conversão alimentar (CA) são apresentados na Tabela 5.

O ganho em peso diário (GPD) diminuiu linearmente $(\mathrm{P}<0,05)$. Tal comportamento pode ser explicado pela diminuição no consumo de NDT (Tabela4). O NRC (1985) sugere consumo em torno de $850 \mathrm{~g}$ de NDT/dia para ganho de $200 \mathrm{~g} / \mathrm{dia}$, para animais com características semelhantes aos utilizados neste trabalho. De acordo Mertens (1994) e Van Soest (1994), o animal tende a aumentar o consumo com rações contendo menores níveis de energia para atender seus requerimentos, até que o enchimento limite este consumo. Porém, este comportamento não foi verificado, uma vez que o consumo não foi alterado, sugerindo que houve efeito de enchimento para todos os níveis de substituição utilizados.

A conversão alimentar aumentou linearmente $(\mathrm{P}<0,05)$ com a inclusão do farelo de palma na dieta, em razão da diminuição no consumo de NDT e de semelhante consumo de matéria seca, com a inclusão do farelo de palma.
Não houve efeito da substituição para os rendimentos de carcaças quente (RCQ) e fria (RCF), uma vez que os animais receberam dietas com semelhante proporção de volumoso:concentrado, portanto, alimento com tempo de retenção no rúmen também semelhante. Então, considerando que todos os animais experimentais permaneceram em jejum sólido por 14 horas e foram abatidos com aproximadamente $32 \mathrm{~kg}$ de PV, pode-se constatar que, em todos os tratamentos, o esvaziamento do trato gastrintestinal (TGI) ocorreu com a mesma velocidade, antes da mensuração do PV. Dessa forma, a resposta observada para RCQ e RCF era esperada, visto que o conteúdo gastrintestinal está diretamente relacionado com estes parâmetros (ARC, 1980; Owens et al., 1993).

De acordo com Petit et al. (1994), quando se estabelece peso para abate, as diferenças para RCQ e RCF são debeladas.

Outro fator de grande importância econômica é a perda de peso da carcaça, que ocorre por evaporação durante o resfriamento e pela perda de suco exsudado nas fases posteriores ao abate (Cia \& Felício, 1978). Observa-se que a inclusão do farelo de palma também 
Tabela 5 - Médias, equação de regressão (ER) e coeficientes de determinação $\left(r^{2}\right)$ e variação $(C V)$ para ganho em peso diário (GPD), rendimento de carcaça quente $(R C Q)$, rendimento de carcaça fria (RCF), perdas por resfriamento (PR), conversão alimentar (CA) e dias em confinamento (DC), em função dos níveis de substituição do milho pelo farelo de palma

Table 5 - Mean, fitted regression equation (RE), coefficients of determination $\left(r^{2}\right)$ and variation (CV) of average daily gain (ADG), dressing percentage of hot carcass (DPHC), dressing percentage of cold carcass (DPCC), loss in cooling (LC), feed: gain ratio (FC) and feedlot days (FD), according to the levels of replacement of corn by forage cactus meal

\begin{tabular}{|c|c|c|c|c|c|c|c|}
\hline \multirow{3}{*}{$\begin{array}{l}\text { Variáveis } \\
\text { Variables }\end{array}$} & \multirow{2}{*}{\multicolumn{4}{|c|}{$\begin{array}{l}\text { Níveis de substituição (\%) } \\
\text { Levels of replacement (\%) }\end{array}$}} & \multirow{3}{*}{$\begin{array}{l}\mathrm{ER} \\
R E\end{array}$} & \multirow[t]{3}{*}{$\mathrm{r}^{2}$} & \multirow[t]{3}{*}{$\mathrm{CV}$} \\
\hline & & & & & & & \\
\hline & 0 & 33 & 66 & 100 & & & \\
\hline GPD (kg/dia) & 0,21 & 0,16 & 0,14 & 0,12 & $\mathrm{Y}=0,2022-0,000893 * \mathrm{FP}$ & 0,97 & 20,66 \\
\hline \multicolumn{8}{|l|}{$A D G(\mathrm{~kg} /$ day $)$} \\
\hline $\mathrm{RCQ}(\%)$ & 0,47 & 0,45 & 0,43 & 0,45 & $Y=0,45$ & - & 7,96 \\
\hline \multicolumn{8}{|l|}{ DPHC (\%) } \\
\hline $\mathrm{RCF}(\%)$ & 0,46 & 0,42 & 0,41 & 0,42 & $\mathrm{Y}=0,43$ & - & 9,97 \\
\hline \multicolumn{8}{|l|}{$\operatorname{DPCC}(\%)$} \\
\hline $\operatorname{PR}(\%)$ & 3,69 & 6,06 & 5,13 & 5,98 & $\mathrm{Y}=5,22$ & - & 65,94 \\
\hline \multicolumn{8}{|l|}{$L C(\%)$} \\
\hline $\mathrm{CA}(F C)$ & 5,71 & 7,48 & 8,54 & 10,07 & $\mathrm{Y}=5,8399+0,042514 * \mathrm{FP}$ & 0,93 & 19,79 \\
\hline $\mathrm{DC}(F D)$ & 45 & 61 & 66 & 77 & $\mathrm{Y}=47,246+0,30257 * \mathrm{FP}$ & 0,96 & 28,31 \\
\hline
\end{tabular}

* Significativo $(P<0,05)$ pelo teste $t$ (Significant $[P<.05]$ by $t$ test $)$. FP - Nível de substituição (Level of replacement).

não influenciou a perda por resfriamento (PR). Dessa forma, é importante salientar que a diferença em porcentagem de suco expelido, não apresenta importância prática que desvalorize a carne de determinado tratamento, visto que os valores estão dentro da amplitude de carnes normais (Alcalde et al., 1999). No entanto, essa diferença apresenta importância comercial quantitativa (Osório et al., 2002), pois o baixo rendimento de carcaça fria pode ser também consequiência da elevada perda de peso das massas musculares durante o resfriamento (Garcia et al., 2000). A PR possivelmente seja mais influenciada por fatores de meio, como oscilações na temperatura da câmara fria, o que provavelmente ocorreu no desenvolvimento deste trabalho.

Os dias em confinamento aumentaram linearmente $(\mathrm{P}<0,05)$, em decorrência do menor ganho de peso dos animais recebendo níveis crescentes de farelo de palma.

Na Tabela 6, são apresentados resultados relativos à análise da receita líquida, considerando-se apenas os custos dos ingredientes das rações e do ganho de peso total dos animais. Verificou-se que, com o aumento dos níveis de substituição, a receita líquida diminuiu, em virtude do maior custo de alimentação para o mesmo ganho de peso no tratamento especifico, demonstrando a inviabilidade econômica do uso de farelo de palma em substituição ao milho.

\section{Conclusões}

A adição do farelo de palma às dietas não alterou o consumo de matéria seca, porém diminuiu o consumo de energia e o ganho de peso, não tendo, portanto, condições de substituir o milho para a alimentação de ovinos em crescimento. Os resultados deste experimento indicam a inviabilidade econômica da substituição do milho moído pelo farelo de palma na dieta de ovinos em crescimento.

Tabela 6 - Receita líquida de acordo com os níveis de substituição

Table 6 - Net income according to the replacement levels Itens Níveis de substituição(\%)

Items Levels of replacement (\%)

\begin{tabular}{lcccc}
\hline U\$/kg de MS & 0 & 33 & 66 & 100 \\
\hline & 0,162 & 0,155 & 0,145 & 0,139
\end{tabular}

$U \$ / k g$ of $D M$

$\begin{array}{lllll}\text { Dias em confinamento } & 45 & 61 & 66 & 77\end{array}$

Feedlot days

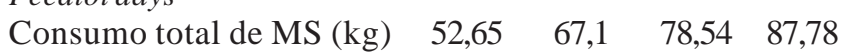

Total DM intake, $\mathrm{kg}$

Ganho de peso total (kg) $\quad 9,45 \quad 9,70 \quad 9,44 \quad 9,0$

Total weight gain, $\mathrm{kg}$

Receita bruta (U\$)

Crude income, $U \$$

$\begin{array}{lllll}\text { Receita líquida(U\$) } & 7,06 & 5,60 & 4,19 & 2,65\end{array}$

Net income, $U \$$

$(\mathrm{U} \$ 1,00=\mathrm{R} \$ 3,00)$. 


\section{Literatura Citada}

AGRICULTURAL RESEARCH COUNCIL - ARC. The nutrient requirements of ruminats livestock. London: Commonwealth Agricultural Bureaux, 1980.351p.

ALCALDE, M.J.; SAÑUDO, C.; OSÓRIO, J.C. et al. Evaluación de la calidad de la canal y de la carne en canales ovinas ligeras del tipo comercial ternasco. Información Técnica Económica Agraria, v.95, n.1, p.49-64, 1999.

ALVES, K.S.; ANDRADE, M.A.; VÉRAS, A.S.C. et al. Níveis de energia em dietas para ovinos Santa Inês: digestibilidade aparente. Revista Brasileira de Zootecnia, v.32, n.6, p.1962-1968, 2003 (Supl. 2).

ANDRADE, D.K.B.; FERREIRA, M.A; VÉRAS, A.S.C. et al. Digestibilidade e absorção aparentes em vacas da raça holandesa alimentadas com palma forrageira (Opuntia ficus indica Mill) em substituição à silagem de sorgo (Sorgum bicolor (L.) Moench). Revista Brasileira de Zootecnia, v.31, n.5, p. 2088-2097, 2002.

ARAÚJO, R.B.A. Substituição do milho por palma forrageira (Opuntia ficus indica Mill e Nopalea Cochenillifera Salmdyck) em dietas completas para vacas em lactação. Recife: Universidade Federal Rural de Pernambuco, 2002. 43p. Dissertação (Mestrado em Zootecnia) - Universidade Federal Rural de Pernambuco, 2002.

CIA, G.; FELÍCIO, P.E. Revisão sobre resfriamento e congelamento de carne. Boletim Técnico da Ciência e Tecnologia da Carne, n.1, 1978. 26p.

DHAKAD, A.K.; GARG, P.S.; AGRAWAL, D.K. Effect of replacement of maize grain with wheat bran on the performance of growing lambs. Small Ruminant Research, v.43, n.3, p.227-234. 2002,

FORBES, J.M. Voluntary food intake and diet selection in farm animal. Wallingford: CAB Internacional, 1995. 532p.

GARCIA, C.A.; MONTEIRO, A.L.G.; SAFFI, F.J. Efeito da substituição do milho pela semente de sorgo-vassoura no desempenho de cordeiros confinados. In: REUNIÃO ANUAL DA SOCIEDADE BRASILEIRA DE ZOOTECNIA, 34., 1997, Juiz de Fora. Anais... Juiz de Fora: Sociedade Brasileira de Zootecnia, 1997. p.370.

GARCIA, I.F.F.; PÉREZ, J.R.O.; OLIVEIRA, M.V.M. Característica de carcaça de cordeiros Texel $x$ Bergamácia, Texel x Santa Inês puros, terminados em confinamento alimentados com casca de café como parte da dieta. Revista Brasileira de Zootecnia, v.29, n.1, p.564-572, 2000.

GERON, L.J.V.; ZEOULA, L.M.; CALDAS NETO, S.F. et al. Substituição do milho pela farinha de varredura Manihot esculenta Crantz em rações para ovinos. 1. Ingestão de matéria seca e valor energético. In: REUNIÃO ANUAL DA SOCIEDADE BRASILEIRA DE ZOOTECNIA, 38., 2001, Piracicaba. Anais... Piracicaba: Sociedade Brasileira de Zootecnia, 2001, p.1219-1220.

MARTINS, A.S.; PRADO, I.N.; ZEOULA, L.M. et al. Digestibilidade aparente de dietas contendo milho ou casca de mandioca como fonte energética e farelo de algodão ou levedura como fonte protéica em novilhas. Revista Brasileira de Zootecnia, v.29, n.1, p.269-277, 2000.

MELO, A.A.S.; FERREIRA, M.A.; VÉRAS, A.S.C. et al. Substituição parcial do farelo de soja por uréia e palma forrageira (Opuntia fícus indica Mill) em dietas para vacas em lactação. I. Desempenho. Revista Brasileira de Zootecnia, v.32, n.3, p.727-736, 2003.

R. Bras. Zootec., v.34, n.1, p.249-256, 2005
MERTENS, D.R. Regulation of forage intake. In: FAHEY JR., G.C. (Ed.). Forage quality, evaluation and utilization. Madison: American Society of Agronomy, 1994. p.450-493.

MERTENS, D.R. Analysis of fiber in feeds and its uses in feed evaluation and ration formulation. In: SIMPÓSIO INTERNACIONAL DE RUMINANTES, REUNIÃO ANUAL DA SOCIEDADE BRASILEIRA DE ZOOTECNIA, 29., 1992, Lavras. Anais... Lavras: Sociedade Brasileira de Zootecnia, p.1-32, 1992.

NATIONAL RESEARCH COUNCIL - NRC. Nutrient requirement of sheep. 6.ed. Washington, D.C.: National Academy Press, 1985. 99p.

NEFZAOUI, A.; BEN SALEM, H. Opuntiae: a strategic fodder and efficient tool to combat desertification in the wana region. Disponível em <http://www.fao.org/ag/AGP/AGPC/doc/ PUBLICAT/Cactusnt/cactus2.htm> Acessado em: $21 \mathrm{de}$ agosto de 2003.

OSÓRIO, J.C.S.; OLIVEIRA, N.M.; OSÓRIO, M.T.M. et al. Produção de carne em cordeiros cruza Border Leicester com ovelhas Corriedale e Ideal. Revista Brasileira de Zootecnia, v.31, n.3, p.1469-1480, 2002 (suplemento).

OWENS, F.N.; DUBESKI, P.; HANSON, C.F. Factors that alter the growth and development of ruminants. Journal of Animal Science, v.71, p.3152-3172, 1993.

PETIT, H.V.; VEIRA, D.M.; YU, Y. Growth and carcass characteristics of beef steers fed silage and different levels of energy with or without protein supplementation. Journal Animal Science, v.72, n.12, p.3221-3229, 1994.

RAMOS, P.R.; PRATES, E.R.; FONTANELLI, R.S.; et al. Uso do bagaço de mandioca em substituição ao milho no concentrado para bovinos em crescimento. 2. Digestibilidade aparente, consumo de nutrientes digestíveis, ganho de peso e conversão alimentar. Revista Brasileira de Zootecnia, v.29, n.1, p.300-305, 2000.

SANTOS, C.L.; PÉREZ, J.R.O.; VASCONCELOS, T.R.; et al. Desempenho e caracteríticas de carcaça de cordeiros Santa Inês abatidos a diferentes pesos. In: REUNIÃO ANUAL DA SOCIEDADE BRASILEIRA DE ZOOTECNIA, 38., 2001, Piracicaba. Anais... Piracicaba: Sociedade Brasileira de Zootecnia, p.1498-1499. 2001.

SANTOS, D.C.; FARIAS, I.; LIRA, M.A. et al. A palma forrageira (opuntia fícus-indica Mill e Nopalea cochenillifera Salm Dyck) em Pernambuco: cultivo e utilização: Recife: IPA, 1997. 23p. (Documentos, 25)

SANTOS, G.R.A.; BATISTA, A.M.V.; CARVALHO, F.F.R. et al. Composição química e degradabilidade da matéria seca de dez clones de palma forrageira (Opuntia e Nopalea). In: REUNIÃO ANUAL DA SOCIEDADE BRASILEIRA DE ZOOTECNIA, 37., 2000, Viçosa, MG. Anais... Viçosa, MG: Sociedade Brasileira de Zootecnia, 2000. p.368.

SILVA, M.F.; BATISTA, A.M.V.; ALMEIDA, O.C. Efeito da adição de capim-elefante a dietas à base de palma forrageira sobre a fermentação ruminal em bovinos. In: REUNIÃO ANUAL DA SOCIEDADE BRASILEIRA DE ZOOTECNIA, 34., 1997. Juiz de Fora. Anais... Juiz de Fora: Sociedade Brasileira de Zootecnia, 1997. p.140-142.

SILVA, D.J.; QUEIROZ, A.C. Análise de alimentos (métodos químicos e biológicos). 3.ed. Viçosa, MG: Universidade Federal de Viçosa, 235p. 2002.

STROBEL, H.J.; RUSSEL, J.B. Effect of pH and energy spilling on bacterial protein synthesis by carbohydrate-limited cultures of mixed rumen bacteria. Journal of Dairy Science, v.69, p.2941-2947, 1986. 
UNIVERSIDADE FEDERAL DE VIÇOSA - UFV. SAEG Sistemas de Análises Estatísticas e Genéticas. Versão 7.1. Viçosa, MG, 1997. 150p. (manual do usuário).

Van SOEST, P.J. Nutritional ecology of the ruminants. 2.ed. Ithaca: Cornell University Press, 1994. 476p.

Van SOEST, P.J.; ROBERTESON, J.B.; LEWIS, B.A. Methods for extraction fiber, neutral detergent fiber and nonstarch polysaccarides in relation to animal nutrition. Journal of Dairy Science, v.83, n.1, p.3583-3597, 1991

VÉRAS, R.M.L.; FERREIRA, M.A.; CARVALHO, F.F.R. et al. Farelo de palma forrageira (Opuntia fícus indica Mill) em substituição ao milho.1. Digestibilidade aparente dos nutrientes. Revista Brasileira de Zootecnia, v.31, n.3, p.13021306, 2002.

WANDERLEY, W.L.; FERREIRA, M.A.; ANDRADE, D.K.B. et al. Palma forrageira (Opuntia fícus indica Mill) em substituição à silagem de sorgo (Sorghum bicolor (L.) Moench) na alimentação de vacas leiteiras. Revista Brasileira de Zootecnia, v.31, n.1, p.273-281, 2002.
ZEOULA, L.M.; PRADO, I.N.; CALDAS NETO, S.F. et al. Substituição do milho pela farinha de varredura sobre consumo voluntário e digestibilidade em ovinos. In: REUNIÃO ANUAL DA SOCIEDADE BRASILEIRA DE ZOOTECNIA, 37., 2000, Viçosa, MG. Anais... Viçosa, MG: Sociedade Brasileira de Zootecnia, 2000. p.483.

Recebido em: 14/08/03

Aceito em: 29/09/04 